\title{
Importance of the Ultrasonography in Diagnosis of Ileal Duplication Cyst
}

\author{
Arzu Gebesce, ${ }^{1}$ Mevlit Korkmaz, ${ }^{2}$ Esengul Keles, ${ }^{1}$ Feride Korkmaz, \\ Kamran Mahmutyazicioglu, ${ }^{4}$ and Hamza Yazgan ${ }^{1}$ \\ ${ }^{1}$ Department of Pediatrics, Fatih University, Istanbul, Turkey \\ ${ }^{2}$ Department of Pediatrics Surgery, Fatih University, Istanbul, Turkey \\ ${ }^{3}$ Department of Anesthesiology, Fatih University, Istanbul, Turkey \\ ${ }^{4}$ Department of Radiology, Fatih University, Istanbul, Turkey
}

Correspondence should be addressed to Arzu Gebesce; agebesce@fatih.edu.tr

Received 12 July 2013; Revised 1 October 2013; Accepted 2 October 2013

Academic Editor: Horia Stefãnescu

Copyright (C) 2013 Arzu Gebesce et al. This is an open access article distributed under the Creative Commons Attribution License, which permits unrestricted use, distribution, and reproduction in any medium, provided the original work is properly cited.

\begin{abstract}
Gastrointestinal duplication cysts are rare congenital anomalies that can be seen in anywhere of the gastrointestinal system from the mouth to the anus. These are prenatally diagnosed through antenatal ultrasonography. However, attention must be paid since these formations might be confused with ovarian or mesenteric cysts. Our patient, who had been diagnosed with ovarian cyst on the ultrasonography performed in another center and with mesenteric cyst based on the abdominal MRI carried out at fifth month of life, presented to our clinic with the only complaint of constipation at 9th month of life. The diagnosis was set through double wall appearance of duplication cyst on the abdominal ultrasonography. The patient's cyst was resected.
\end{abstract}

\section{Introduction}

Gastrointestinal duplication cysts are rare congenital anomalies that can be seen in anywhere of the gastrointestinal system with a prevalence between $1: 4500$ and $1: 10000$. The most common location is ileum. Signs and symptoms differ based on the location, although mostly it manifests as acute abdominal or intestinal obstruction before 2 years of life. More rarely serious complications such as gastrointestinal bleeding or malignant degeneration may also occur. Colonic duplication cysts are further rare. Gastrointestinal duplication cysts are usually seen as two different forms as lumencommunicating and noncommunicating types. The most common form is cystic and noncommunicating type [1-3]. The treatment is surgery and total excision is the method of choice. In this report, our patient, who had been diagnosed with ovarian cyst on the ultrasonography (USG) performed in another center and with mesenteric cyst based on the abdominal MRI carried out at fifth month of life, presented to our clinic with the only complaint of constipation at 9th month of life. The diagnosis was set in our clinic through double wall appearance on the abdominal ultrasonography. The patient's cyst was resected.

\section{Case Report}

On the second-level USG ordered at 23rd gestational week of a healthy mother aged 32, a hypoechoic formation with $5 \mathrm{~mm}$ and $9 \mathrm{~mm}$ in size which was observed at the right side of the bladder in the pelvis was considered and followed up as ovarian cystic formation.

The patient was born by normal vaginal route at term, weight of $3000 \mathrm{gr}$. The patient's Apgar score was found 8 in minute 1 and 9 in minute 5 . No pathologic finding was found at the physical examination of the patient. On the contrast enhanced abdominal MRI performed in a different center when the patient was five months old showed simple cyst. It also revealed two lobule-contoured, thick-walled cystic lesion with diameters of $19 \mathrm{~mm}, 12 \mathrm{~mm}$, and $5 \mathrm{~mm}$ in the right lateral part of the abdomen. The mass was diagnosed as mesenteric cyst, and the patient was followed up for this diagnosis. 


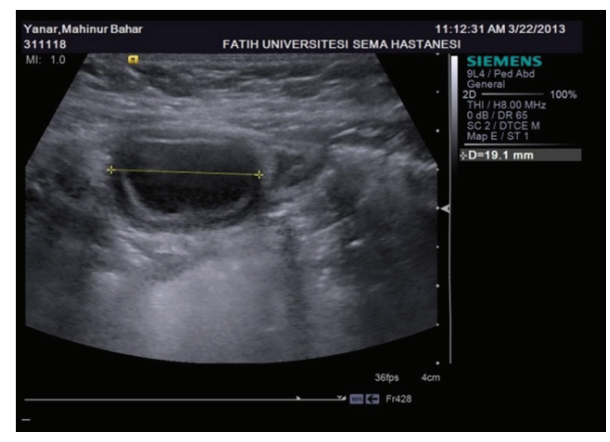

FIGURE 1: On sonography, we found that the hypoechoic outer wall of the cystic structure was continuous with the hypoechoic outer wall of the adjacent ileal bowel, and the hypoechoic outer wall of the cystic structure was continuous with the hypoechoic outer wall of the adjacent ileal bowel.

Our patient presented to our clinic at her 9th month of life with only complaint of constipation. On physical examination, biochemical and hematological values were found normal in the patient who had a growth and development of 50 percentile. On her USG performed in our clinic, $19 \mathrm{~mm}$, $12 \mathrm{~mm}$, and $5 \mathrm{~mm}$ in size the duplication cyst having double wall appearance was observed in the right lower quadrant. On sonography, we found that the hypoechoic outer wall of the cystic structure was continuous with the hypoechoic outer wall of the adjacent ileal bowel, and the hypoechoic outer wall of the cystic structure was continuous with the hypoechoic outer wall of the adjacent ileal bowel (Figure 1).

An exploratory laparotomy was performed. On the exploration, a duplication cyst of $19 \mathrm{~mm}, 12 \mathrm{~mm}$, and $5 \mathrm{~mm}$ in size was found at the ileal level at an approximate distance of $45 \mathrm{~cm}$ from the ileocecal valve (Figure 2). About $7 \mathrm{~cm}$ ileal segment involving the cyst was resected through distal and proximal bowel clamps. No complication was observed in postnatal followups of the patient. Histopathological examination of the piece was consisted with intestinal duplication cyst.

\section{Discussion}

Alimentary tract duplications are uncommon congenital anomalies that occur mostly in paediatric patients. The first reported case was made by Calder in 1733 [4]. Duplications arise from disturbances in the embryonic development of the gastrointestinal tract. Several major theories have been proposed for the formation of duplications at various sites, including the aberrant luminal recanalisation theory and the diverticular theory [5]. Others include the split notochord theory which explains the formation of neurenteric duplications and associated vertebral anomalies. Recently, Bishop and Koop suggested that environmental factors such as trauma or hypoxia in early foetal development were likely to be responsible when multiple duplications are found in association with anomalies such as malrotation or atresia [6].

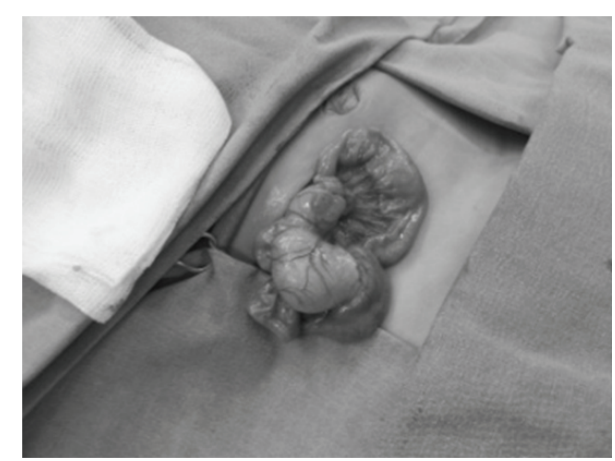

FIgURE 2: On exploration, a duplication cyst of $19 \mathrm{~mm}, 12 \mathrm{~mm}$, and $5 \mathrm{~mm}$ in size was found at the ileal level at an approximate distance of $45 \mathrm{~cm}$ from the ileocecal valve.

Primary cystic lesions seen in the fetal and neonatal periods include renal, choledochal ovarian, mesenteric, duplication cysts, or Meckel's diverticulum. Double wall appearance of duplication is monitored on USG as a hyperechoic edge surrounding the mucosal wall inside and a hypoechoic wall surrounding the smooth muscular layer outside. However, the double wall sign can also be a characteristic of Meckel's diverticulum or sonographic artifacts. Furthermore, Meckel's diverticulum can have a spherically shaped cystlike appearance, which is similar to an enteric duplication cyst, on sonography [7-9]. Although Meckel's diverticulum is located on the antimesenteric border and communicates with the adjacent bowel lumen, in contrast to the duplication cyst, these differentiating features are often not visible on USG or CT $[10,11]$.

Presentation of intestinal duplications is variable depending on size, shape, and type of mucosa. They may be asymptomatic and discovered accidentally at surgery. They may be minimally symptomatic and associated with vague abdominal pain, constipation, or failure to thrive [12]. Our patient presented to our clinic at her 9th month of life with only complaint of constipation.

The enteric duplication cyst can be associated with malrotation. In half of the cases, there are associated malformations, the most frequent of these being esophageal duplications, followed by vertebral abnormalities [13]. No malrotation and malformations as esophageal duplications and vertebral abnormalities were seen in our case.

Our patient, who had been diagnosed with ovarian cyst on the ultrasonography (USG) performed in another center and with mesenteric cyst based on the abdominal MRI carried out at fifth month of life, presented to our clinic with the only complaint of constipation at 9th month of life. On USG duplication cyst was diagnosed through the double wall appearance which is specific for duplication cyst. The treatment option proposed for duplication cysts is surgery and the surgery of choice is excision because of the potential complications [14]. In our patient also we performed surgical excision under general anesthesia. 


\section{Conclusion}

In conclusion, ultrasonography is an inexpensive and practicable imaging modality in evaluation of intra-abdominal cystic lesions. Although it seems asymptomatic and rare, this type of cyst must be surgically excised because of the potential complications and malignant degeneration.

\section{Conflict of Interests}

The authors declare that they have no conflict of interests.

\section{References}

[1] J. Schalamon, J. Schleef, and M. E. Höllwarth, "Experience with gastro-intestinal duplications in childhood," Langenbeck's Archives of Surgery, vol. 385, no. 6, pp. 402-405, 2000.

[2] P. S. Puligandla, L. T. Nguyen, D. St-Vil et al., "Gastrointestinal duplications," Journal of Pediatric Surgery, vol. 38, no. 5, pp. 740744, 2003

[3] A. Geller, K. K. Wang, and E. P. DiMagno, "Diagnosis of foregut duplication cysts by endoscopic ultrasonography," Gastroenterology, vol. 109, no. 3, pp. 838-842, 1995.

[4] S. J. Keckler and G. W. Holcomb, "Alimentary tract duplications," in Ashcrafts's Paediatric Surgery, G. W. Holcomb and J. P. Murphy, Eds., pp. 517-525, Sanders Elsevier, Philadelphia, Pa, USA, 5 edition, 2010.

[5] G. W. Holcomb III, A. Gheissari, J. A. O’Neill Jr., N. A. Shorter, and H. C. Bishop, "Surgical management of alimentary tract duplications," Annals of Surgery, vol. 209, no. 2, pp. 167-174, 1989.

[6] H. C. Bishop and C. E. Koop, "Surgical management of duplications of the alimentary tract," The American Journal of Surgery, vol. 107, no. 3, pp. 434-442, 1964.

[7] S. R. Shankar, S. V. Parelkar, S. A. Das, and A. B. Mathure, "An antenatally-diagnosed solitary, non-parasitic hepatic cyst with duodenal obstruction," Pediatric Surgery International, vol. 16, no. 3, pp. 214-215, 2000.

[8] B. Matteo, R. M. Deise, and D. D. Marcelo, "Sonographic findings of Meckel's diverticulitis in children," The American Journal of Roentgenology, vol. 180, no. 2, pp. 425-428, 2003.

[9] M. M. Ferro, R. Milner, L. Voto et al., "Intrathoracic alimentary tract duplication cysts treated in utero by thoracoamniotic shunting," Fetal Diagnosis and Therapy, vol. 13, no. 6, pp. 343347,1998 .

[10] A. M. Fink, E. Alexopoulou, and H. Carty, "Bleeding Meckel's diverticulum in infancy: Unusual scintigraphic and ultrasound appearances," Pediatric Radiology, vol. 25, no. 2, pp. 155-156, 1995.

[11] G. Cheng, D. Soboleski, A. Daneman, D. Poenaru, and D. Hurlbut, "Sonographic pitfalls in the diagnosis of enteric duplication cysts," The American Journal of Roentgenology, vol. 184, no. 2, pp. 521-525, 2005.

[12] D. L. Angela and M. H. Christine, "From the archives of the AFIP. Meckel diverticulum: radiologic features with pathologic correlation," Radiographics, vol. 24, no. 2, pp. 565-587, 2004.

[13] P. Srivastava, A. N. Gangopadhyay, V. kumar et al., "Noncommunicating isolated enteric duplication cyst in childhood," Journal of Pediatric Surgery, vol. 44, no. 7, pp. e9-e10, 2009.
[14] E. L. Wrenn Jr., "Alimentary tract duplications," in Pediatric Surgery, K. W. Ashcraft, Ed., pp. 527-539, Elsevier Saunders, New York, NY, USA, 2th edition, 2000. 


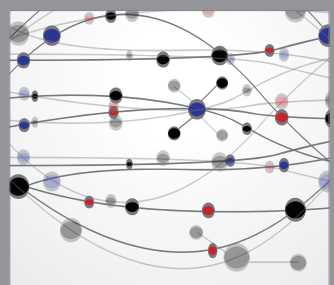

The Scientific World Journal
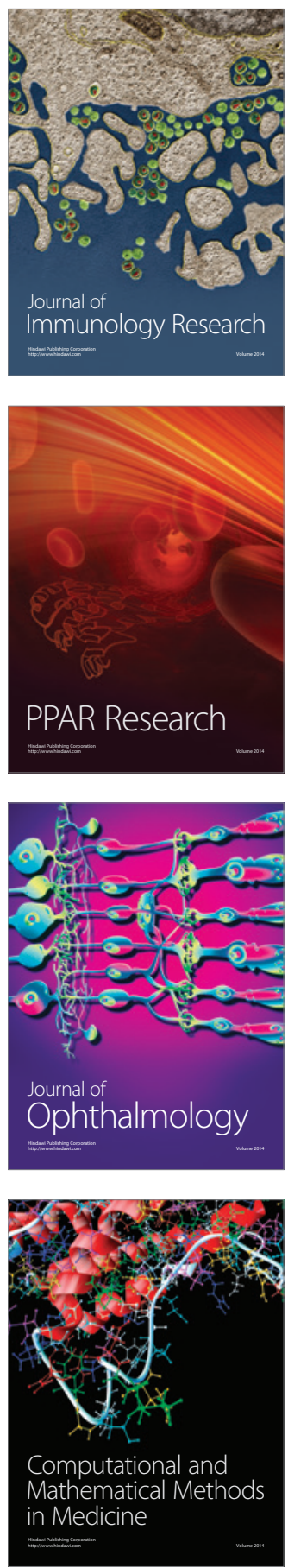

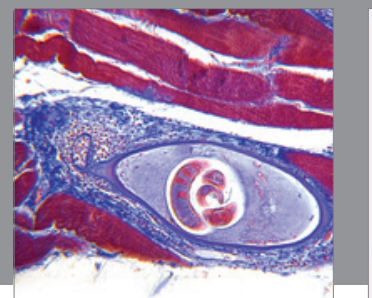

Gastroenterology

Research and Practice
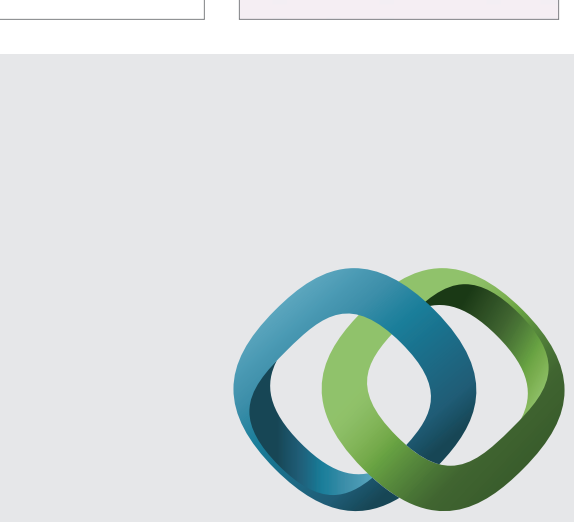

\section{Hindawi}

Submit your manuscripts at

http://www.hindawi.com
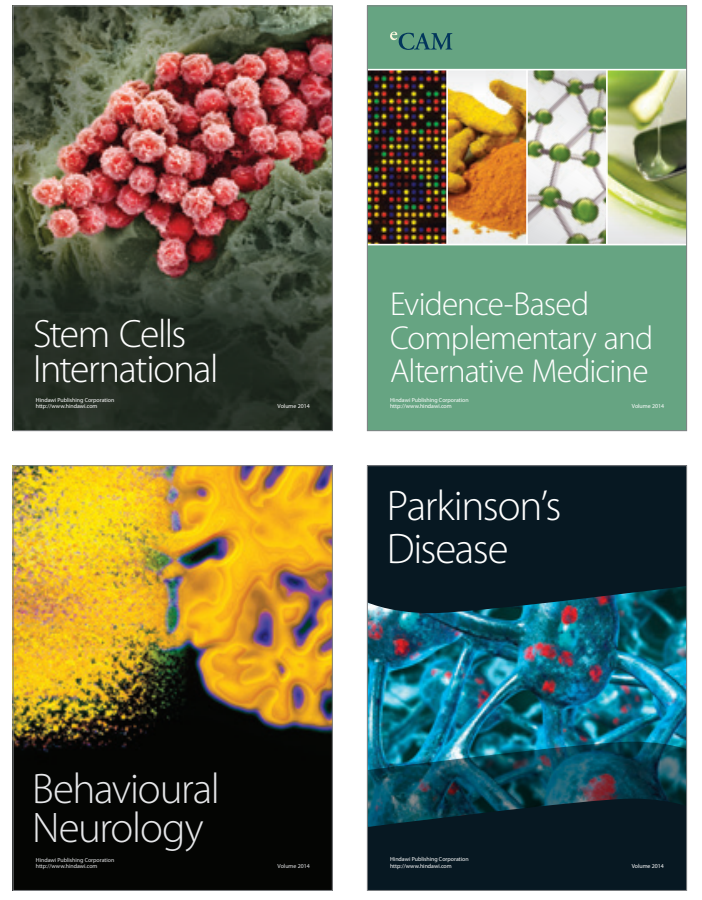
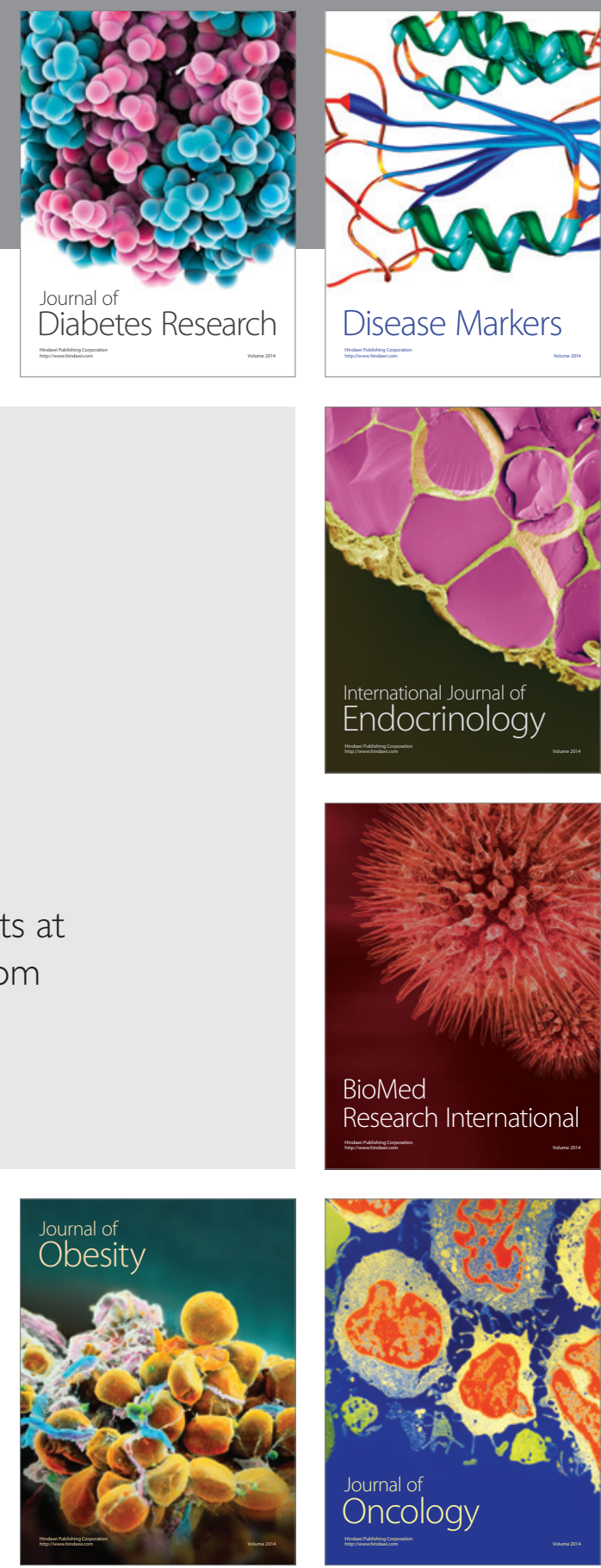

Disease Markers
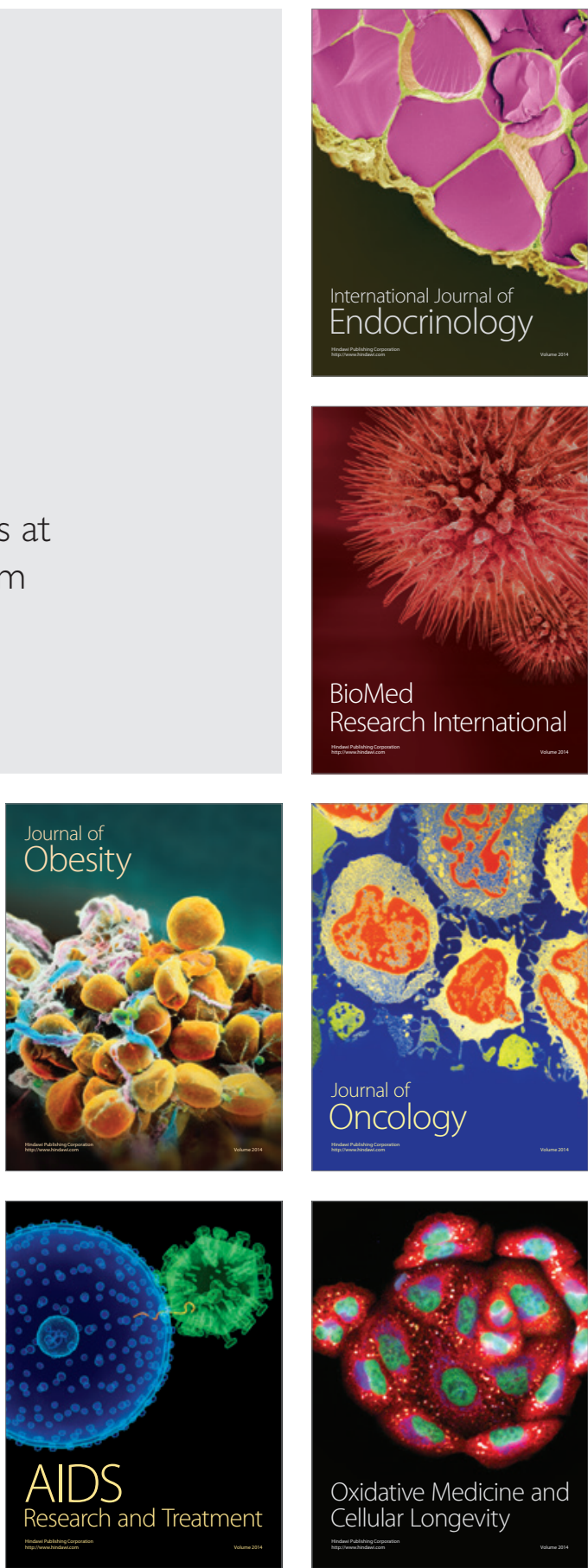